\title{
Murburn concept: a paradigm shift in cellular metabolism and physiology
}

https://doi.org/10.1515/bmc-2020-0002

received November 25, 2019; accepted January 2, 2020.

\begin{abstract}
Two decades of evidence-based exploratory pursuits in heme-flavin enzymology led to the formulation of a new biological electron/moiety transfer paradigm, called murburn concept. Murburn is a novel literary abstraction from "mured burning" or "mild unrestricted burning". This concept was invoked to explain the longstanding conundrum of maverick physiological dose responses and also applied to remodel the prevailing understanding of drug metabolism and cellular respiration. A conglomeration of simple ideas grounded in the known principles of thermodynamics and reaction chemistry, murburn concept invokes catalytic/functional roles for diffusible reactive species or radicals. Hitherto, diffusible reactive species were primarily seen as toxic agents of chaos, non-conducible to the maintenance of life-order. Since the murburn paradigm offers a distinctly different perspective for several biological phenomena, researchers holding conventional views of cellular metabolism pose a direct conflict of interests to the advancement of murburn concept. Murburn schemes are poised to integrate numerous metabolic motifs with holistic physiological outcomes; redefining pursuits in biology and medicine. To advance this agenda, I present a brief account of murburn concept and point out how redundant ideas are still advocated in some prestigious journals.
\end{abstract}

Keywords: xenobiotic/drug metabolism; cellular/ aerobic respiration; pharmacokinetics; oxidative phosphorylation; murburn; reactive oxygen species (ROS); bioenergetics; cytochrome; reductase; thermodynamics; kinetics; mechanism; scientific philosophy; research practice.

*Corresponding author: Kelath Murali Manoj, Satyamjayatu: The Science \& Ethics Foundation,Snehatheeram, Kulappully, Shoranur-2 (PO), Kerala, India-679122, E-mail: murman@satyamjayatu.com

\section{A philosophical prelude and the story of murburn concept}

As Karl Popper put it, scientific advancement fundamentally rests on the practice of empirical falsification. He had correctly argued that obtaining a number of favorable findings cannot be taken as a justification of a hypothetical belief. (For, all that is needed for jettisoning that belief is one datum that does not abide by the hypothesis!) However, it is human societies rooted in 'multiple belief systems' that churn out scientists. Since individuals in a society have multiple subjective beliefs and diverse interests thereof, Michael Polanyi had argued that subjectivist justifications are a matter of reality in social and scientific practices. As a result, falsification or refutation of long-held misplaced beliefs becomes a painfully uphill process. This reality gives rise to a temporal distribution of Dionysians and Apollonians, as Albert Szent-Gyorgyi mooted. The majorities of Apollonians establish and expand an extant paradigm through systemic/gradual process, maintaining a paradigmatic status quo. A Dionysian subscribes to Newtonian first law to usher in the famed Thomas Kuhn's "paradigm shift" and expects the Apollonians to check out the former's new paradigm, and reorient post verification. But, as famously quoted by Max Planck (“A new scientific truth does not triumph by convincing its opponents and making them see the light, but rather because its opponents eventually die, and a new generation grows up that is familiar with it."), Apollonians dig in deeper, resort to an exaggerated Newton's third law, consider the Dionysian (ideas) anathema, and react with unwarranted excess. And it is such a paradigm shift that I discuss herein, by advocating murburn concept as a fundamental and ubiquitous mechanism that helps us better understand and explain cellular metabolism and physiology. The new ideas may pose immense discomfort to several well-established scientists' interests. However, in the greater picture and in the longer run; countless lives and immeasurable resources can be saved with the new ideas. Further, we cannot lose out on the commonality and communicability 
of simple quantitative logic, the quintessential tool of science. Science is a fact-based, empirically verifiable endeavor; of finding the most optimal rationale to holistically explain natural phenomena and misplaced vested interests or cognitive dissonance deserve little merit in its pursuit. So, a forthright modus of advocating murburn concept is justified by the- (i) deontological negativistic path warranted by scientific philosophy and (ii) utilitarian outcome of safeguarding the interests of the "many justified rights" over "a few misplaced wrong". It is banking on such a moral and rational logic that I present to you murburn concept.

In the late 1990s, I was working as a postdoctoral research associate in Lowell Hager's (Member, National Academy of Sciences, USA) lab at University of Illinois, Urbana-Champaign, when a serendipitous and intriguing observation came my way. It was seen that low concentrations of azide could enhance one-electron oxidations catalyzed by heme (halo)peroxidases (HPO) by several fold. This was when it was a known fact that azide is a heme active-site binding ligand, and therefore, an inhibitor of catalytic activity. The pursuit of a logical explanation for this simple observation led to a concept that several heme enzymes employed diffusible reactive species to bring about catalysis outside the active site, on the surface or periphery of the enzyme, or in bulk milieu. This idea could not be published for the next several years because few would accept a theory that an enzyme could work with selectivity (say, choosing a substrate $B$ from a mixture of $A, B, C \& D$ ) and specificity (attacking the substrate $B$ at say, $\beta$ position, when there are $\alpha, \beta, \gamma$ and $\omega$ loci available), if the reaction was mediated outside the active site. (Enzyme-mediated biocatalysis invoked Fisher's "lock \& key" or Koshland's "induced fit" theories, leading to the classical Michaelis'/Eyring's "Enzyme+Substrate transition state complex". Doubts prevailed on how the diffusible species mediated reaction could afford choice between substrates, without the identification of molecular topological/electrostatic features.) But later, when presented with reproducible observations and deductions from multiple heme enzyme systems, Lowell came around and graciously endorsed my views [1], and lent his name to some works that were originally initiated in his lab [2-4]. Although a major perception-difference on heme-enzyme's interaction with diffusible reactive oxygen species (DROS) had been published in 2001 [5], the foundation of murburn concept was based in two seminal communications I made in 2006 [6, 7]. Since Lowell recognized my views on HPO, such works were cited well ( $>200$ citations) but the same was not to be for the cytochrome P450 systems.
The choice of 'murburn' as the word to capture the essence of a new paradigm in redox biology was rooted in personal disposition, and made in 2014. Via poster presentations in international conferences like DMPK-2015 (NIPER-Mohali) in India and GRC-Drug Metabolism-2015 (Holderness), MECC-2015 (Chicago) and ISSX-2015 (Orlando) in USA [8], the idea and its application in microsomal xenobiotic metabolism (mXM) were further vetted with peers. Finally, murburn concept (with the new name) was published as a mechanistic explanation for heme/flavin enzymes in 2016, via four original communications [9-12]. The core ideas are expanded upon in my group's later papers and a mechanistic snapshot is given in Figure 1 and its legend. In toto, by the end of 2019, murburn concept was used to explain aerobic respiration also and about two dozen [2-5, 7-26] peer-reviewed papers on murburn concept have been published in reputed journals, approximately half of which directly cite the new term 'murburn' in title/abstract/text [9-12, 20-26]. Further, another invited article is in press [27] and three key unpublished works on murburn concept are also available on reputed pre-print portals [28-30]. In this letter, I shall defend/advocate murburn concept (as defined in abstract) below).

\section{A brief on the grounding and significance of murburn concept}

We know that life processes involve the transfer of electrons or groups/moieties for effecting temporal changes amongst the molecules/ions that comprise living matter. At a molecular level, this is what constitutes as the "activities of life". Heat energy and chemical energy (in the form of molecules like ATP) are the most common sources by which the electromagnetic force is channeled to serve the function of life. So, all types of "intelligent expressions of life" depend on this "non-intelligent" powering logic. That is, without ATP and heat, we could neither think an iota nor blink an eye. It is in the abovedefined contexts of biology and chemico-physics that murburn concept plays its protagonist role. A chaotic statistical/stochastical interactive equilibrium scheme can afford two key desired features necessary for ordered life- (i) primordial directive principles for selectivity and specificity and (ii) inherent on/off or gradable controls. Therefore, without the presence of a "supra-molecular intelligence" (like what is afforded by the organelle of nucleus within a cell or the organ of brain within an animal's body) and before the evolution of affinity or sorption 

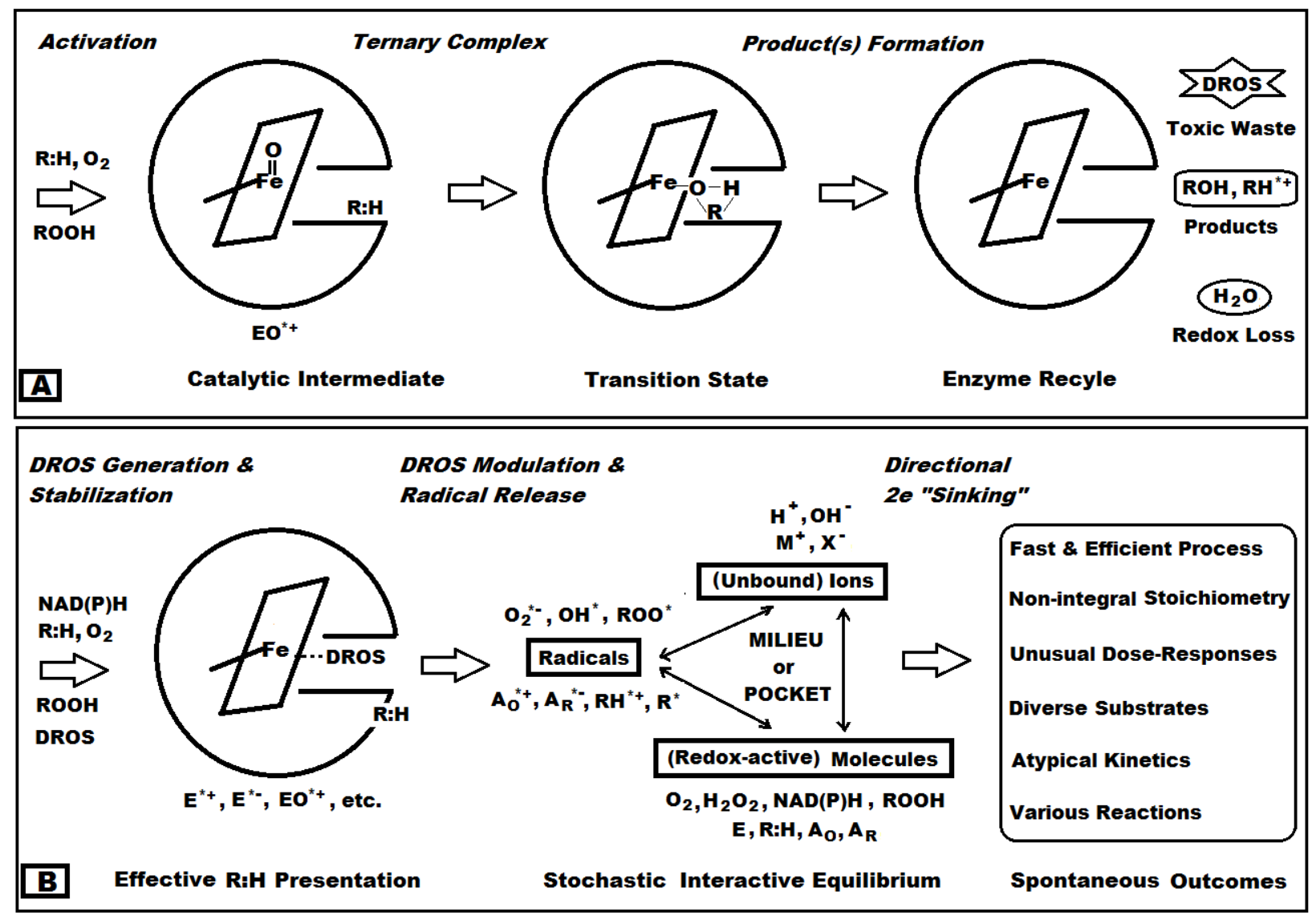

Figure 1: A summary of the classical (A) and murburn (B) schemes for heme-enzyme (peroxidase, cytochrome P450, catalase, etc.) reactions. In $A$, post the charging of the heme center by the activators, the enzyme forms a 2e-deficient intermediate, which directly interacts with the final substrate bound at the distal heme pocket. DROS like superoxide and hydroxyl radicals are deemed as wasteful reaction products in this scheme. Water formation could occur at the heme center, also leading to redox loss. In B, The heme center serves as a DROS producer/ stabilizer/modulator and the apoprotein would serve to enhance reaction efficiency by presenting the substrate (bound at an allosteric locus, preferably adjacent to the site of DROS release. The salient feature of the murburn scheme is an interactive equilibrium between redox-active molecules, ions, and radicals. This scheme is inclusive of the active-site classical concepts (not stressed here!) and also sees reactions outside the distal pocket as a means to affect catalysis. (E stands for enzyme, $A_{0}$ and $A_{R}$ are oxidizable and reducible additives, $\mathrm{M}^{+}$and $\mathrm{X}$ - are positively and negatively charged ions respectively. (It must be noted that the murburn scheme does not negate the classical scheme, but expands upon the same. That is, the murburn mechanism is a bigger set of events that could incorporate the classical enzyme cycle pathways.)

based modalities of direction and regulation, the coarser features of murburn concept were needed for the origin, evolution, and sustenance of life [24]. This is explained analogically further in the paragraph below, using both etiology and phenomenology.

Burning is a spontaneous phenomenon usually seen when molecular oxygen reacts with a suitable material. It usually generates gases like carbon dioxide and steam, plus lot of heat and light. The flames may comprise of these gases and their radical cum ionic intermediates. A more controlled burning occurs in a fuelled engine. Gasoline is burnt in a chamber to produce expanding gases, keeping dissipation by heat to a minimal, to give usable work. Imagine a process similar to this, but at a much smaller scale, in a confined (mured- old English) and milder mode without flames, occurring in cellular systems, in which the fuel substrate is brought into "a reactor with catalysts" at suitable concentrations, and oxygen flows in at a steady rate, to dynamically generate more reacted products and less heat. This is murburn concept. In essence, it is an unrestricted interactive or reactive paradigm of molecules and unbound/bound ions (which make up living matter!) to generate transient radicals, to carry out useful electron transfer or group transfer functions necessary for the cell. 
The intermediary radicals are usually centered on oxygen, (as it is a diradical, but other moieties could also serve the role, albeit less efficiently) and the reactions are staged at the phospholipid interface, for enhancing selectivity and minimizing collateral damage. The selectivity of this 'burning' is quite like when a cloth daubed in oil is set on fire, the fabric is burnt to a much lesser extent, as long as the oil is available for reaction [24]. More sophisticatedly, this is quite like using a knife (oxygen centered radical) in a kitchen (organelle) [27]. Though a knife may cut the user's hand (leading to oxidative damage of proteins and lipids), gloves (redox enzymes) and cutting boards (anti-oxidants) and adept handling (steady-state transport) enable one to exploit the knife's potentials without overt damage to the kitchen/user.

\section{Application of murburn concept in ecobiology and medicine}

Since murburn concept explains the activity of HPO, it accounts for the recycling of lignocellulosics and halogenated biorganics in the environment. In many ways, the complex liver microsomal xenobiotic metabolism (mXM) system is quite comparable to the simpler HPO system [24]. In pharmacokinetics research, as seen from latest edition of textbooks and reviews [31, 32], the explanatory paradigm based on $\mathrm{P} 450$ cam model is that the binding of a xenobiotic to a liver microsomal cytochrome P450 (CYP) induces a conformational and redox change in the protein, which facilitates electron transfer from a unique flavoenzyme CYP-reductase (CPR) via proteinprotein binding and long-distance electron tunneling. This high-fidelity enzyme-substrate binding is considered necessary to lead to oxygen-activation at the heme-center, and it is a distal heme-pocket localized hemeFe- $O$ species that purportedly metabolizes the diverse drug or xenobiotic molecules that enter the body [31-32]. We challenged such an improbable multi-molecular serial reaction chemistry scheme by quoting a simple evolutionary logicit is highly unlikely that the diverse xenobiotics could all have affinity-based binding within the heme active site and therefore, long-term binding of the substrate in the active site is not favored by Occam's razor [7-9, 12]. Also, we showed that diffusible reactive oxygen species (DROS) could easily relay electrons between the few/sole CPR and numerous/diverse CYPs [10]. Elaborating on mXM system further, we had presented FIFTY distinct theoretical and experimental arguments disclaiming the erstwhile P450cam model found in textbooks and supporting the new murburn theory. This was again published in a reputed journal focusing on the subject [12]. In the last three and a half years, only two non-self citations [33, 34] were made on such an important work that directly affects the trillion dollar drug industry, which caters to the $\sim 7.5$ billion humans + unknown number of animals!

The extant paradigms of cellular biochemistry did not afford sufficient scope to explain maverick physiological dose responses because both enzyme-mediated catalysis and receptor-ligand binding mediated signaling cascades are unidirectional [21]. That is- increments in a molecule's concentration or a stimulus can give a concomitant increase in the responsive signal, and this may reach a saturation point, after which the molecule/stimulus may or may not become toxic/detrimental. So, the activity profiles obtained are either bell-shaped or hyperbolic. Since the involvement of murburn scheme affords a concentration-based stabilization of radical intermediates, and since such intermediates are more stable at lower concentrations, and also since the intermediates may have different order of reactions in a complex set of interactive equilibriums, we can explain higher activities at lower or discrete concentrations (when there might not be any such activity at higher concentrations!). Using the HPO and mXM models, we provided the first tangible molecular kinetics mechanism for hormetic and idiosyncratic dose responses, which was predicted first [11] and demonstrated recently in a leading journal focusing on the subject [21]. Such works showed that murburn reaction model was a metabolically and physiologically viable concept.

Drawing on the similarities between the relatively simpler HPO-mXM systems and the more complex mOxPhos (mitochondrial oxidative phosphorylation) system, we proposed a hearth or nuclear reactor model for mitochondrial physiology [20, 24]. In the murburn purview, the various membrane complexes of the mOxPhos machinery (which generates ATP and heat, the powering logic of life!) are present to activate oxygen and moderate the DROS, to effectively present it for reacting with ADP bound on the surface (just like the $m X M$ system!), leading to ATP formation. By the end of last year, five important papers that comprehensively overhauled the perceptions in the field and advocated the murburn paradigm were published [20, 22-25]. In these papers, we have highlighted the simple disclaimer (which someone with a graduation-level biochemistry awareness can understand!) that the chemiosmotic paradigm is seriously flawed because there are $\sim 10^{6}$ membrane proteins (purported to be proton pumps) within a mitochondrion but there is only $<6$ free protons in the matrix. So, proton pumps cannot work there! Further, we pointed out that 
oxygen could easily diffuse and react with all membrane redox-active proteins, and therefore, there cannot be an "electron transport chain". Further, Complex V cannot be the physiological ATP synthase because the protein has higher affinity for ATP (and not ADP!) and because such a structure-function attribution would surely qualify to be the anti-evolution "irreducibly complex" argument. Our recent review on moXPhos lists THIRTY reasons why the erstwhile Keilin-Mitchell-Boyer explanation is misplaced and murburn rationale is more probable [26]. Some unpublished works/write-ups on- (i) critical dissection of the mechanism of oxygenic photophosphorylation [28] (ii) effect of cyanide on mOxPhos [29], and (iii) redefining the roles of $\mathrm{NADH}+$ proton+oxygen in cellular respiration and the connection of metabolism and physiology [30]- are also now available at reputed preprint portals. Our cyanide paper at the bioRxiv preprint site alone has garnered more than a 1000 views (with over 200 pdf downloads) in a few months [29]. But then, in spite of presenting concrete experimental and quantitative arguments backed by literature, it is still unpublished and few seem to cite such works and reorient!

Therefore, by critiquing the acclaimed/published works forthrightly (as per Popper's philosophy), I hope that people would notice and turn around! While the $m X M$ research group would resist any change with utmost vehemence (because of the monetary stakes involved!), the mOxPhos group is an elite/sophisticated one and deals with a very fundamental aspect of life. Therefore, seven (I through VII) recent papers published (in reputed and pertinent journals) on bioenergetics related phosphorylation routines are focused here, with the hope that making a splash in this field will get murburn concept greater recognition in the other realms. In this regard, Table 1 would show all concerned that the bioenergetic mOxPhos routine is not any extraordinary mechanoelectrical scheme, but just a more complex heme/flavinDROS reaction systema like HPO or mXM systems. This is particularly because the systems of HPO, mXM and mOxPhos could adequately function with a reductionist setup of "the hemeFe catalysts + superoxide combination" $\mathrm{OR}$ "the whole enzymatic system + $\mathrm{NADPH}+\mathrm{O}_{2}$ " setups. This experimental similarity in simulation clearly implies that radical DROS are involved as the functional intermediates in all cases. With this prelude, I address the crux of this communication.

I. First on the agenda is to present a rebuttal to Dr. Sunil Nath's response [35] regarding my original critique [36] of his works/ideas on mOxPhos, published in Biophysical Chemistry.
(A) One could make a point-wise orderly rebuttal (like what one would do upon receiving a peer review). Starting from the Abstract-

\begin{abstract}
"The radical statements and assertions are shown to contradict a vast body of available knowledge that includes i) pioneering single-molecule biochemical and biophysical studies from the respected experimental groups of Kinosita, Yoshida, Noji, Börsch, Dunn, Gräber, and Dimroth etc., ii) state-of-the-art X-ray and EM/cryo-EM structural information garnered over the decades by the expert groups of Leslie-Walker, Kühlbrandt, Mueller, Meier, Rubinstein, Sazanov, and Pedersen on ATP synthase, iii) the pioneering energybased computer simulations of Warshel....”
\end{abstract}

I have nothing against the structural information generated by these venerated scientists, whether through simple or sophisticated techniques. However, the fact is that structural information or single-molecule experiments or simulations do not give any conclusive picture on physiological dynamics. I have also used the insights from their data. It is the interpretation of data where I differ with the peers. When there is an Apollonian mandate to prove something, people would go to elaborate lengths to establish the same. (Boyer mooted phosphohistidine when Slater was in vogue and later, when Mitchell was on the swing, the very Boyer proposed a proton-centric rotary scheme, didn't he?) It is quite another agenda to have an exploratory outlook and prioritize on the crucial links and pieces, to solve a lasting conundrum. Whatever change in the Complex V-mediated catalysis Dr. Nath proposed is through ideation based on its available structure and extant theories. (Both Mitchell and Nath are of the school that ideating before collection of the pertinent facts are more important in solving a problem!) What I have proposed is based on experimental evidence gathered through several years of working hands-on with redox enzymes and DROS, and the details available on mOxPhos system. The structure-function correlations and overall chemico-physical logic hitherto attributed in mOxPhos do not make good scientific sense, is my other argument. Making a list of leading researchers or techniques they employed does not accrue counter-logic in this regard. My criticism of the extant theory is clearly explained in my group's papers published in recent times and succinctly captured in the "Letter to Editor" I wrote. Dr. Nath resorts to some unnecessary strategies, diverting attention.

\footnotetext{
"Valid objections against Mitchell's chemiosmotic theory and Boyer's binding change mechanism put forth by Manoj have been addressed satisfactorily by Nath's torsional mechanism of ATP synthesis and two-ion theory of energy coupling and published 10 to 20 years ago, but these papers are not cited
} 
Table 1: Three reaction systems where murburn concept was applied to afford greater awareness and predictable accuracy. All three systems' salient reactions can be simulated in vitro with the reductionist constitution of hemeprotein and superoxide. All reactions show complicated pH profiles, atypical kinetics and maverick effects upon the introduction of select additives.

\begin{tabular}{|c|c|c|c|c|c|c|c|c|}
\hline System & Cofactors & Protein(s) & Ions & $\begin{array}{l}\text { pH \& Ambi- } \\
\text { ance }\end{array}$ & e-Source/Sink & Major Reaction & Products & Relevance \\
\hline HPO & $\begin{array}{l}1 \text { heme-Fe } \\
\left(\mathrm{Mn}^{2+} \text { optio- }\right. \\
\text { nal) }\end{array}$ & $\begin{array}{l}\text { One glycosylated } \\
\text { polar protein, } \\
\text { halo-peroxidase } \\
\text { (HPO) }\end{array}$ & $\begin{array}{l}\mathrm{H}^{+}, \mathrm{Cl}^{-} / \\
\mathrm{Br} / \mathrm{I} ; \mathrm{mM} \\
\text { levels of } \\
\text { halide } \\
\text { needed }\end{array}$ & $\begin{array}{l}\text { Acidic pH; } \\
\text { aqueous } \\
\text { system }\end{array}$ & $\begin{array}{l}\mathrm{H}_{2} \mathrm{O}_{2} \text { and other } \\
\text { organic hyd- } \\
\text { roperoxides; } \\
\text { diverse organics } \\
\text { like di-ketones, } \\
\text { sulfides, olefins, } \\
\text { etc. }\end{array}$ & $\begin{array}{l}\text { Halogen atom } \\
\text { transfer, and/ } \\
\text { or various types } \\
\text { of substrate } \\
\text { oxidation. }\end{array}$ & $\begin{array}{l}\mathrm{R}^{*}, \mathrm{R}-\mathrm{R}^{\prime}, \\
\mathrm{RCl}, \\
\mathrm{RCl}-\mathrm{R}^{\prime} \mathrm{OH}, \\
\mathrm{R}=0 \text {, } \\
\mathrm{ROCl}, \\
\text { etc. }\end{array}$ & $\begin{array}{l}\text { Halogenated } \\
\text { bioorganics, } \\
\text { recycling of } \\
\text { lignocellulo- } \\
\text { sics, peroxi- } \\
\text { somes, etc. }\end{array}$ \\
\hline$m X M$ & $\begin{array}{l}2 \text { heme-Fe, } 2 \\
\text { Flavins } \\
\text { (Fe-S optio- } \\
\text { nal) }\end{array}$ & $\begin{array}{l}\text { 1+1 Hemoprote- } \\
\text { ins (P450, Cyt. } \\
b_{5} \text { ), } 1 \text { Flavo- } \\
\text { protein; } 1 \text { Fe-S } \\
\text { protein; (Cyt. } b_{5} \\
\& \text { Fe-S proteins } \\
\text { are optional) }\end{array}$ & $\begin{array}{l}\mathrm{H}^{+}, \mathrm{OH} \text {, } \\
\text { ionic } \\
\text { strength is } \\
\text { crucial for } \\
\text { electron } \\
\text { transfers! }\end{array}$ & $\begin{array}{l}\text { neutral pH; } \\
\text { Interfacial } \\
\text { system, } \\
\text { uncoupling } \\
\text { high without } \\
\text { lipid embed- } \\
\text { ding }\end{array}$ & $\begin{array}{l}\mathrm{NADPH}+\mathrm{O}_{2} \\
\text { (works poorly } \\
\text { with } \mathrm{NADH} \text { ); } \\
\text { diverse subst- } \\
\text { rates (primarily } \\
\text { hydrophobic) } \\
\text { with various func- } \\
\text { tional groups and } \\
\text { non-activated } \\
\text { carbons }\end{array}$ & $\begin{array}{l}\text { Oxygen atom } \\
\text { insertion or } \\
\text { hydroxyl moiety } \\
\text { transfer. } \\
\text { and/or various } \\
\text { types of subs- } \\
\text { trate oxidation } \\
\text { and bond clea- } \\
\text { vages. }\end{array}$ & $\begin{array}{l}\mathrm{ROH}, \\
\mathrm{R}=0 \text {, etc., }\end{array}$ & $\begin{array}{l}\text { Drug } \\
\text { metabolism, } \\
\text { Steroid and } \\
\text { prosta- } \\
\text { glandin } \\
\text { pathways, } \\
\text { etc. }\end{array}$ \\
\hline mOxPhos & $\begin{array}{l}2 \text { flavins, } 2 \\
\text { Cu-centers, } \\
\text { several } \\
\text { heme-Fe and } \\
\text { multitudes of } \\
\text { Fe-S centers, } \\
\text { Several qui- } \\
\text { nones, etc. }\end{array}$ & $\begin{array}{l}5 \text { large multi- } \\
\text { meric protein } \\
\text { complexes } \\
\text { formed of several } \\
\text { tens of prote- } \\
\text { ins; also form } \\
\text { supercomplexes, } \\
\text { Both membrane- } \\
\text { embedded and } \\
\text { soluble proteins }\end{array}$ & $\begin{array}{l}\mathrm{H}^{+}, \mathrm{OH} ; \\
\mathrm{HPO}_{4}^{2-} \\
\left(\mathrm{Mg}^{2+}\right) ; \\
\mathrm{mM} \text { levels } \\
\text { of } \mathrm{Pi} \\
\text { needed }\end{array}$ & $\begin{array}{l}\text { neutral pH; } \\
\text { closed lipid } \\
\text { vesicles with } \\
\text { membrane- } \\
\text { laden } \\
\text { catalysts and } \\
\text { proton inlets }\end{array}$ & $\begin{array}{l}\mathrm{NADH}+\mathrm{O}_{2} ; \\
\text { amphipathic sub- } \\
\text { strate } 1(\mathrm{AdP}-\mathrm{OH} \\
\text { or } \mathrm{ADP}) \text { and } \\
\text { soluble substrate } \\
2(\mathrm{P}-\mathrm{OH} \text { or } \mathrm{Pi})\end{array}$ & $\begin{array}{l}\text { Phosphate } \\
\text { group transfer, } \\
\text { water and heat } \\
\text { formation. }\end{array}$ & $\begin{array}{l}\text { AdP-OP } \\
\text { (ATP), } \\
\mathrm{H}_{2} \mathrm{O}, \mathrm{H}_{2} \mathrm{O}_{2}\end{array}$ & $\begin{array}{l}\text { Bioenergetic } \\
\text { phospho- } \\
\text { rylations, } \\
\text { thermo- } \\
\text { genesis, } \\
\text { fundamental } \\
\text { homeosta- } \\
\text { sis, etc. }\end{array}$ \\
\hline Equation & HPO & \multicolumn{7}{|c|}{$\begin{array}{l}\mathrm{RH}+\mathrm{H}^{+} \mathrm{X}+\mathrm{H}_{2} \mathrm{O}_{2} \rightarrow \mathrm{RX}+2 \mathrm{H}_{2} \mathrm{O} \\
2 \mathrm{H}_{2} \mathrm{O}_{2} \rightarrow \mathrm{O}_{2}+2 \mathrm{H}_{2} \mathrm{O}\end{array}$} \\
\hline & $m X M$ & \multicolumn{7}{|c|}{$\begin{array}{l}\mathrm{RH}+\mathrm{NADPH}+\mathrm{O}_{2} \rightarrow \mathrm{ROH}+\mathrm{NADP}^{+}+\mathrm{OH}^{-}\left(+/-\mathrm{DROS}^{-}\right) \\
\mathrm{RH}+\mathrm{NADPH}+\mathrm{H}^{+}+\mathrm{O}_{2} \rightarrow \mathrm{ROH}+\mathrm{NADP}^{+}+\mathrm{H}_{2} \mathrm{O}(+/-\mathrm{DROS})\end{array}$} \\
\hline & mOxPhos & \multicolumn{7}{|c|}{$\begin{array}{l}\text { (x) AdP-OH + (x) P-OH + NADH + } \mathrm{H}^{+}+\mathrm{O}_{2} \rightarrow(x) \mathrm{AdP}-\mathrm{OP}+\mathrm{NAD}^{+}+(x) \mathrm{H}_{2} \mathrm{O}+\mathrm{H}_{2} \mathrm{O}_{2} \\
\text { (x) AdP-OH + (x) P-OH + FADH }+\mathrm{O}_{2} \rightarrow(x) \text { AdP-OP }+\mathrm{FAD}+(x) \mathrm{H}_{2} \mathrm{O}+\mathrm{H}_{2} \mathrm{O}_{2}\end{array}$} \\
\hline
\end{tabular}

by him. This communication shows conclusively and in great detail that none of his objections apply to Nath's mechanism/ theory."

Dr. Nath's claim that he had already captured the essence/details of my comprehensive overhaul of the KMB paradigm is a blatant violation of reality. Further, anyone could see that in my brief correspondence, a refutation "letter to the editor" of a mere $~ 950$ words with six references, I could not possibly go into the elaborate aspects of the subtle differences between Mitchell's chemiosmosis and Nath's two-ion theories and cite all his papers. Given the mandate, I just pointed out clearly that both chemiosmosis and counter-ion exchange proposals fall within the essentially "ETC involving, proton-centric, TMP-based, Complex V synthesizes ATP" paradigm. The title and the discussion of my refutation were focused upon this commonality. Dr. Nath's new theory is just the same old TMP-based chemiosmosis replaced by TMPbased counter-ion exchange. Table 1 of my recent $A B B$ review paper [26] has the five fundamental tenets or components of the extant explanations for mOxPhos(i) protein complexes (protons/ion translocators), (ii) oxygen/DROS, (iii) TMP/pmf, (iv) ATP synthesis in 
steady state, (v) connectivity between electron transfer (from NADH to $\mathrm{O}_{2}$ ) and ATP synthesis- pitted against the murburn explanation. Any discerning individual can see that Dr. Nath's explanation (with all its subtle distinctions from chemiosmosis) still falls under the Keilin-MitchellBoyer model for each of the 5 criteria! My agenda here is primarily to dislodge the entire scaffold of the erstwhile paradigm and I do not mince words in this pursuit. Therefore, Dr. Nath makes a false claim with respect to the crux of my refutation, as his ionic mechanism does not explain the radical reaction chemistry of mOxPhos, and why there are so many one-electron redox centers in the system. Next, Dr. Nath fails to mention the word "murburn" (the mechanism floated to replace the extant theories!) in his elaborate response and does not cite my works advancing the murburn explanation. In contrast, I have not failed to cite him in my three papers within the references listed in my brief refutation letter. Who is cognitively dissonant or evasive, is something that the discerning reader and editor can decide.

\begin{abstract}
"As a researcher dedicated to the fundamental problem of ATP synthesis for over three decades, I am greatly concerned by the numerous contradictions with established experimental facts and the lack of knowledge of seminal works in the field of bioenergetics displayed by the author of a recent Letter to the Editor on the subject. It is claimed that, a) there is no rotation/torsion in the membrane-bound FO portion of $F_{1} F_{0} A T P$ synthase, $b$ ) that there is no ion translocation by the enzyme complexes, and c) that the F1FO does not synthesize ATP."
\end{abstract}

I had respected Dr. Nath for his commitment to the field and my refutations were purely professional and scientific. In stark contrast, Dr. Nath resorts to unwarranted measures. Points a) through c) are false attributions made to my work and to my persona. a) I have never claimed that there is no torsion in $\mathrm{F}_{0}$. b) I have never said anything on ion translocation by enzyme complexes. (I have definitely said that mitochondrial complexes cannot work as proton pumps. But here, Dr. Nath cannot consider my 'proton' to be equivalent to his 'ion'; for- his histrionics were over the roof when I alluded to the matrix-ward entry of cations/protons in my article's title!) Dr. Nath has failed to see that my explanation for thermogenesis [23] hinges on anionic DROS transport across the mitochondrial membrane! c) I have only said that Complex V cannot be the physiological ATP synthesis agent and never said that Complex V cannot make ATP. (If I had said anything to the effect of what Dr. Nath construes, I must surely be someone he portrays me as- an ignoramus who does not understand the vast literature of bionergetics or even the fundamentals of enzymology!) Dr. Nath must present factual information in a debate. Instead, he makes false attributions now, after staking false claims earlier!

Reading Dr. Nath's paper further made me decide that it did not merit that a point-wise consideration was given to his response. For, he sidetracked criticisms "irrationally" by- calling me names like foolhardy, smart alec, willy-nilly, etc. OR alluding to me as careless OR portraying me as a man lacking experience/awareness in the field OR making false attributions to my works/writing OR indulging in histrionics and unnecessary blame-games OR conveniently overlooking my group's commissioned works OR campaigning to the mass psychology and deliberately goading peers by insinuating that I am looking down at their works OR highlighting a typo error as a gross violation of decency OR wondering how my works were published OR counseling me condescendingly on how I should prove my ideas OR by insinuating that I paid the journals for getting my works published in open access portals, etc. I have cited only a few civility transgressions, and I leave it to the Editor and readers to decide on the issue.

If Dr. Nath would have stuck to the crux of the discussion or even addressed the last part of my letter, it would have sufficed. All that Dr. Nath had to do was address the Sturm et al. PNAS (2015) paper cited in my brief refutation [36] as reference number 6. This paper was the only one that was neither his nor mine. Quoting this crucial work, the conclusive paragraph of my letter clearly states that in the eukaryotic Plasmodium, Complex V (his theory's ATP-synthesizing agent!) was found to be dispensable in certain phases of life of that protozoan. We all know that ATP synthesis by oxidative phosphorylation is essential to all aerobic organisms and therefore, the theory that Complex V is the physiological ATP synthesizer is untenable. Dr. Nath DISREGARDS this conclusive argument in his research approach and in his elaborate response! Instead, he seizes the opportunity to project his theory as the consensus one (and tries to rally the support of all major researchers, who I don't think are aligned with him anyway!), when no well-known textbook cites his works! Most would agree that even today, Mitchell's chemiosmosis theory serves as the 'global pivot' in bioenergetics. It is ironic how Dr. Nath could happily criticize Mitchell or Boyer but he cannot be criticized! I am into this exercise to call out the misplaced beliefs and find more accurate explanations. In that regard, my scathing criticisms of extant theories have hit bull's eye and the new explanation I have floated makes sense of what we know till date. If something comes along that does not fit my explanation, and someone argues with a logic that 
makes the murburn scheme 'improbable', my ideas too should be jettisoned! Dr. Nath does not present any valid defense for his ideas (there is not one argument presented to show why Complex $V$ is the physiological ATP synthase in the mOxPhos reaction system!) and when he does not attack my ideas to cause any significant dent (several dozens of bulleted arguments at the end of my papers were left untouched, and those that he did address- were highly unsatisfactory responses!), it is highly unlikely that we could get more accurate explanations by my sparring with him. (Please note again that he does not cite my works in this regard!) Regardless, one must make justice to the current episode and therefore, I proceed.

(B) Dr. Nath admittedly does not present any explanation for how Complexes I through IV function or why respirasomes exist or why oxygen is actually needed in the system or how electrons from NADH power the ATP synthesis. But he resorts to a 'consensus' to cushion his inabilities to address my arguments in the context. How does this logic work? On one end, he claims to havea unique theory which is different from Keilin-Mitchell-Boyer and then, he also says that his beliefs are in consensus with the major researchers' views (who clearly subscribe to the Keilin-Mitchell-Boyer paradigm). The fact is I did consider the Nath explanation and the RCPE model (in spite of some mechanistic differences and I have explained my rationale in this regard earlier) as essentially similar proposals, and I have already disclaimed and discredited the consensus beliefs! In lieu, I have given novel, simpler, and elaborate structure-function correlations and chemical reactions (thermodynamically and kinetically viable!) involved in the process, which he has not addressed. My group has also demonstrated (both by activity assay and through direct quantification) that in the presence of DROS, ADP + Pi gives ATP and also shown that this reaction is inhibited by the global respiratory toxin of cyanide. Dr. Nath shows dissonance/ignorance of such works and lectures me to do what he would want done- what high-handed cheeks!

(C) The crux of the issue is: Researchers continue to assume that Complex V functions both as ATPase and ATPsynthase in mitochondria. If this were to be, how can the mitochondrion or Complex V "know/decide" when/ how to synthesize ATP and when/how to hydrolyze it? As Dr. Nath mis-projects, I am not refuting Complex V's ability to bind to ADP/ATP or synthesize ATP in an equilibrium driven fashion. The fact is that Complex $\mathrm{V}$ has more than 10 million folds higher affinity for ATP (compared to ADP) and is a demonstrable ATPase. This reality condemns it to be a physiological ATPase, even though it can have some equilibrium driven ATP synthesis (which could also be aided by ionic differentials in whole mitochondrial or reductionist systems). This simple statement explains all that Dr. Nath holds on to or advocates, in support of his ideas! (For the curious ones, the implications of murburn concept can be seen even in the ionic differentials, as I have duly pointed out in my Biochemistry Insights paper by quoting Stoin et al.'s finding, ref. \#74 of the same paper.) Besides, we have clearly shown that Complex V driven equilibrium process can only lead to sub-nanomolar to picomolar ranges of ATP, as opposed to the approximately millimolar levels found in mitochondria [26]. We have also shown how the DROS-driven murburn paradigm can achieve the physiological ATP levels [26]. Our JBSD paper discusses the thermodynamics/kinetics of a purported Complex V mediated ATP synthesis in mitochondria and in prokaryotes [25]. We have also cited in these two papers $[25,26]$ how some earlier researchers had shown that DROS gave ATP synthesis in vivo (in photophosphorylationTyszkiewicz \& Roux, 1987 and oxidative phosphorylationMailer, 1990). Dr. Nath conveniently sidetracks such critical facts/arguments against his view, and which favor the murburn theory. He does not address murburn model's crux or details, and just binges on the argument that his work is an incremental progression on others', whereas my view just 'garbages' all perceptions in the field. He calls my exertions as "stunts of a smart fool" that could lead to "dangerous" consequences. Any interested researcher can find my latest work on the subject uploaded on Nov. $9^{\text {th }}$, 2019 at OSF preprints (https:// osf.io/hx4p9), co-authored with Prof. Nikolai Bazhin, a seasoned thermodynamics expert from Russian Academy of Sciences. In this seminal paper, we have elaborated on the metabolic roles of $\mathrm{NADH}+$ protons+oxygen and correlated it to the homeostatic cellular physiology of water/osmosis and the observation of trans-membrane potential. This work is again solidly grounded in thermodynamics and reaction chemistry. Yes, I do claim to make a theory that appeals to holistic phenomenology, and have not confined myself to just Complex V (as Dr. Nath does!). Dr. Nath portrays my efforts to make "greater sense" as a misplaced egoistic venture, and says in all "humility" that he leaves certain domains to some chosen people! I don't subscribe to his approach. (It is this entrenched approach which did not allow researchers to see the commonality between the HPO, $\mathrm{mXM}$ and mOxPhos systems, all involving one-electron redox centers and DROS, as shown in Table 1.) In my pursuits, I try to find and fit ideas that give the bigger chemico-physical picture. I have $>20$ years of hands-on research experience on heme-flavin enzymes, which is what the mitochondrial respiratory system is. As a scientist, I have changed perceptions earlier and I am entitled to question entrenched belief 
systems further. Any scientist worth his/her mettle has the moral and intellectual responsibility to spar on a fair and rational basis, and not take the focus away from the crux of the issue. Dr. Nath should read our published papers, particularly the recent ones in JBSD and ABB (standard format journals with reputed editorial boards and several decades' publication history!) in 2019 [25, 26]. Since Dr. Nath seems to be disinclined towards that, in the next point, I shall just allude to the relevant contexts presented in these two papers against his/extant proposals and in favor of murburn model.

(D) A concerned one can read section 4.3 to 4.5 of our JBSD paper [25], which presents elaborate evidence for the murburn scheme of mOxPhos, and when taken in conjunction with our explanation for cyanide toxicity [29], the discerning mind can decide. Then, points 1 through 30 of my recent review at $\mathrm{ABB}$ would show an item-wise predictability comparison of the extant theories with murburn model. Thereafter, Section 5.3 of the review and the penultimate paragraph plus arguments A through $\mathrm{E}$ at the end discount Complex V's function as physiological ATP synthase. Section 6 should show thermodynamics/ kinetics analyses that Complex $\mathrm{V}$ cannot be a physiological ATP synthase as it can give only pM levels of ATP [26]. Section 7 shows how murburn scheme can give mM levels of ATP. Finally, Section 9 would give five simple and straight reasons to think in favor for a one-electron coupling scheme of NADH oxidation to generate ATP (or, murburn concept). One just needs to explore with an open-mind: why should the humungous numbers of proteins have so many one-electron redox centers (accessible to oxygen) and ADP-sites and why should they make DROS? We have already presented ample evidence and arguments that ATP synthesis is a simple chemical reaction, not an elaborate trans-membrane electro-mechanical stunt sponsored by Complex V! It is high time that we gave oxygen its due! Surely, it does not just sit at Complex IV and wait for time to make water! (I urge the really concerned to see the last two paragraphs of this write-up that summate arguments against KMB model and conclude with support for murburn paradigm.)

II. A very recent paper in EMBO Journal titled "Individual cristae within the same mitochondrion display different membrane potentials and are functionally independent" by Wolf et al., from Orian Shirihai group, UCLA [37] and support for their ideas in the same issue by Michael Schlame, NYUSM (titled-Mitochondrial cristae as insulated transformers of metabolic energy") [38], found my critical attention. This paper apparently created waves and ripples, and hogged significant media limelight.
When I requested the Editor-in-Chief of EMBO $J$ for a refutation opportunity (with $c c$ to the authors, including the pertinent arguments), the editorial team refused saying that my arguments were irrelevant! I differ in the strongest terms and would like the scientific community to judge the issue. Here is the relevant portion of the abstract, and the images (redrawn and relabeled in Figure 2).

\begin{abstract}
"The mitochondrial membrane potential $\left(\Delta \Psi_{\mathrm{m}}\right)$ is the main driver of oxidative phosphorylation (OXPHOS). The inner mitochondrial membrane (IMM), consisting of cristae and inner boundary membranes (IBM), is considered to carry a uniform $\Delta \Psi_{\mathrm{m}}$. However, sequestration of OXPHOS components in cristae membranes necessitates a re-examination of the equipotential representation of the IMM. We developed an approach to monitor $\Delta \Psi_{\mathrm{m}}$ at the resolution of individual cristae. We found that the IMM was divided into segments with distinct $\Delta \Psi_{\mathrm{m}}$, corresponding to cristae and IBM. $\Delta \Psi_{\mathrm{m}}$ was higher at cristae compared to IBM. Treatment with oligomycin increased, whereas FCCP decreased, $\Delta \Psi_{\mathrm{m}}$ heterogeneity along the IMM. Impairment of cristae structure through deletion of MICOS-complex components or Opa1 diminished this intramitochondrial heterogeneity of $\Delta \Psi_{\mathrm{m}}$....... Altogether, our data support a new model in which cristae within the same mitochondrion behave as independent bioenergetic units, preventing the failure of specific cristae from spreading dysfunction to the rest."
\end{abstract}

Simple conceptual logic (as directed by Occam's razor) cannot support a structural scheme depicted in Figure 11 of their paper. While the proposed structure makes some "appeal" in 2D, it is far-fetched in 3D and notions of reality. For, the structural understanding is that cristae are not just 2D villi or finger-like inward protrusions of the IBM. This is depicted in the modified image of a simple mitochondrial model below in Figure 3. Mostly, the cristae are, rather, shelf like invaginations of the IBM that span (at various densities) through the entirety of the mitochondrial spherocylinder cross-section. The "pinching off" effect within cristae (that should lead to insulation across a distance of several nanometers in all dimensions), by a purported functioning of MICOS complex, leading to "isolated cristal lumen pools within matrix" is "unthinkable" (for the lack of a better word!). This effect would need a deterministic placement and functioning of the MICOS complex along the IBM in defined and protracted/disconnected points "a priori" in 3D geometry and some unknown way to insulate an ionic medium with a component that is not present within that medium! (These aspects are pointed out in the image with bold blue vertical lines on the distal side of the mitochondrion.) Such requisites can only be justified by resorting to highly "irreducibly complex" and "supramolecular intelligence" and "non-perceivable forces/ mechanism" logic lines. 


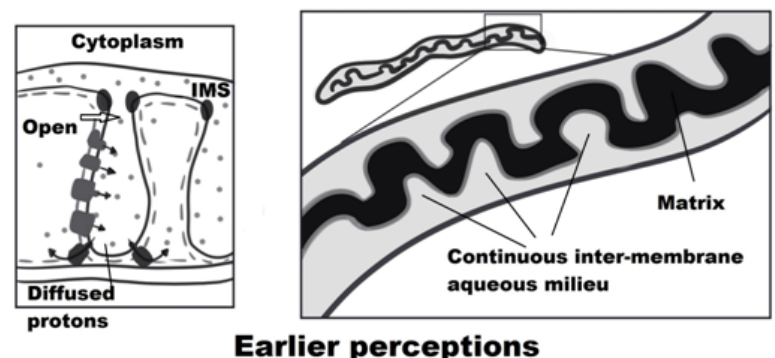

Earlier perceptions

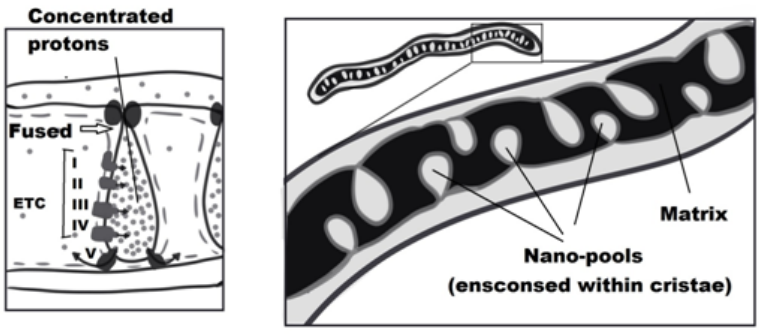

Purported finding

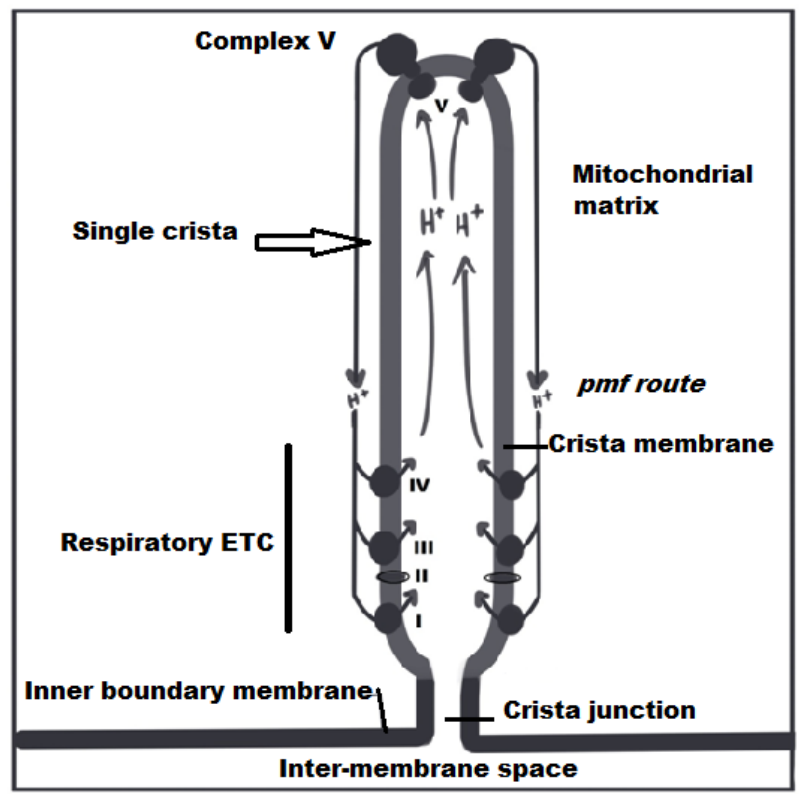

Figure 2: The main message of Wolf et al paper is redrawn, along with Schlame's image supporting the ideas mooted by Shirihai group. Quite simply, the researchers have the proton counts totally wrong, as it is only finger-countable! Schlame supports their finding with a beautifully ordered arrangement of ETC and cyclically directional flow of protons! Such a wishful portrayal is a betrayal of fundamental molecular awareness in chemistry.

Experimental evidence (with "seeing is believing" perspective) does not support the scheme proposed by the authors. It is a well-known concept amongst microscopists that there is no definite shape or pattern for the cristae (as shown in Figure 4) and the mitochondrial shape and internal cristae architecture could also vary significantly within a given (type of) cell within several minutes, upon changing environmental conditions. Secondary aqueous pools within mitochondria are NOT known to result owing to a purported closure or fusion at the cristae junctions of IBM. Anastamosis of cristae may occasionally be seen within the matrix (say, in the honeycomb structure), but this is not owing to any strictures at the IBM cristae junctions. The scenario projected is a "blinded" view of mitochondrial structure or architecture, to keep the chemiosmotic idea floating. I have scanned through several hundreds of TEM images of various mitochondria brought out by researchers through decades and I am yet to see any visual evidence to the scheme proposed by the researchers. On the contrary, the cristae junctions at the outer periphery only show a broader crossectional dimension, instead of a constriction! We know that TEM has far better resolution than the fluorescence microscopy techniques employed by the researchers. Clearly, fusion of membranes at the crista junctions of IBM (near the OMM, outer mitochondrial membrane) or some "magical insulation by MICOS complex" is a mere speculation (which is now necessitated by the entrenched perspective, to keep the redundant chemiosmosis-proton motive force idea alive). To re-iterate: TMP is not what drives oxidative phosphorylation, it is an outcome of the same! There are only $\sim 6$ protons in the physiological mitochondrion, not as copious as shown in Figure 11 of Wolf et al. paper.

Refutation of Schlame's support for Wolf et al.'s interpretations: Since mitochondria are practically aprotic, the mirage diagram showing "spatial distribution of proton-motive lines of force" (as one draws magnetic lines of force in space!) can best be understood only by him! For example, why should the pumped protons by Complex IV (let me keep reminding all that there are little protons to pump in the mitochondria!) go upward to Complex V when the IBM is a much better option as the OMM is equilibrated with cytoplasm? Is there any instance of a proton motive force in the real world? In real instances of electrical conduction via metal wires (where one talks about electron motive force), even an electron does not get translocated from one end of conductor to the other in real space at the speed of light (which is the practical rate of conduction in metals). And electrons have practically negligent mass and occupy least space, in comparison to protons! If the authors and Schlame are talking about a Grotthuss "proton-hopping" mechanistic relay through hydrogen bonds along the cyclic trans-membrane route, then a TMP cannot build [20, 22]. The whole depiction is 

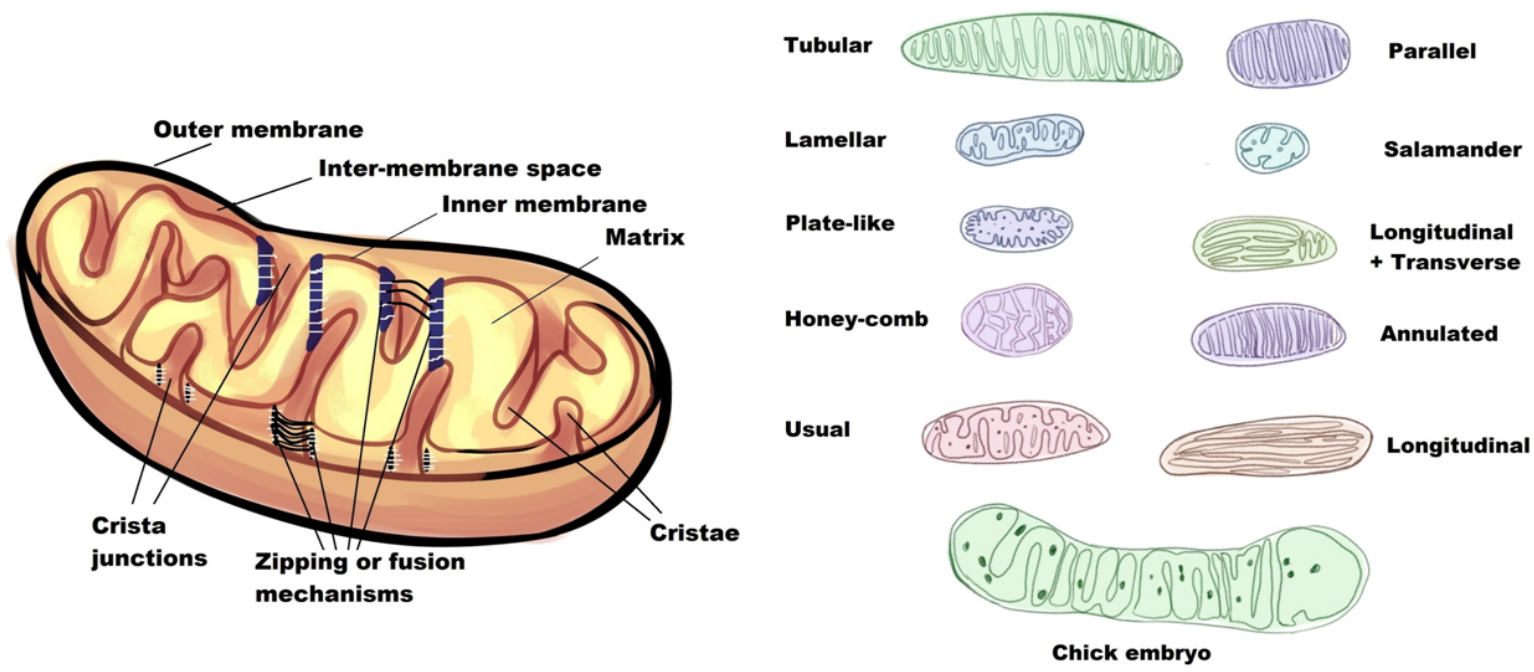

Figure 3: The spatial arrangement of MICOS complex needed for Wolf et al proposals to realize in common mitochondrial cristae, along with some other types of mitochondria.

a mirage, impossible and unimaginable! Why do these researchers not read critical works that have already dissected such false concepts? Who or what puts the membrane complexes in such ordered linear arrangement that the ETC concept solicits? These are mere speculations that have no bases in reality. Further, what is meant by "individual cristae operating with independence" and "transformers of metabolic energy"? What is the measuring of a membrane potential? How can a fluorescence probe (a single molecule) convey a two-point concept of potential difference?

Explanation for Wolf et al.'s findings by murburn concept: TMP occurs due to the presence of DROS. The molecular probe is clearly DROS sensitive. There are loci in the mitochondria with a higher density of DROS (owing to a higher density of DROS-producing redox proteins there!), and that is the reason why one sees higher fluorescence in those places. When one puts in FCCP, a known interfacial DROS/proton modulator, DROS dynamics are altered and homogenized, thereby decreasing the TMP. When one puts in oligomycin, the cationic pore of Complex $\mathrm{V}$ is blocked, thereby minimizing proton entry into matrix, resulting in an enhanced accumulation of anionic DROS at places and enhancing TMP. Obviously, altering of MICOS complexes would disrupt cristae structures and therefore, affect DROS's spatio-temporal distribution. Nothing they have done and found can be interpreted or correlated to the message that they convey! Their work supports the murburn model.
Following through the EMBO $J$ publication above, it was interesting to note that media coverage liken mitochondria to Tesla battery packs (as Schlame called cristae "insulated transformers"). Mitochondria are simple chemical reactors, which have membrane involutions for enhancing catalysts' (protein complexes) loads, using a radical reaction protocol. A Tesla battery is usually a patented ion based technology designed to deliver a fixed potential difference (easily rechargeable upon depletion, without generating much heat) across two terminals. For this, the company uses several independent cells in a desired configuration, to give constant potential difference. Comparing the potentials there with the TMP in mitochondria (or membrane potential, as erroneously used by the authors) is a grave conceptual error. The cristae of mitochondria in Wolf- Shirihai system cannot be compared to the cells in a Tesla battery, as one does not tap the potential difference in mitochondria at any two specific points, quite unlike the arrangement in the battery. In other words, the reaction of ATP synthesis is discretized in space-time within the mitochondrial matrix/ inner membrane interface and not confined to one locus! Also, it is the potential in Tesla battery that we tap for doing useful work whereas the TMP in mitochondria results due to the useful activity of ATP synthesis occurring in the matrix. Quite simply, there is no analogy in structural or functional modularity. I hope the distinction is clear. The need to venture into such futile directions result only because we still consider Mitchellian TMP as the driving force of ATP synthesis! 
III. Another paper by Momcilovic et al [39], with David Shackelford as the leader, was recently published in Nature, with the title- "In vivo imaging of mitochondrial membrane potential in non-small-cell lung cancer." A part of the abstract is reproduced below-

\begin{abstract}
“.........Mitochondria maintain oxidative phosphorylation by creating a membrane potential gradient that is generated by the electron transport chain to drive the synthesis of ATP. ...... Here we measure mitochondrial membrane potential in nonsmall-cell lung cancer in vivo using a voltage-sensitive, positron emission tomography (PET) radiotracer known as 4- $\left.{ }^{18} \mathrm{~F}\right]$ fluorobenzyl-triphenylphosphonium $\left({ }^{18} \mathrm{~F}-\mathrm{BnTP}\right)^{4}$. .... The use of ${ }^{18}$ F-BnTP PET imaging enabled us to functionally profile mitochondrial membrane potential in live tumours."
\end{abstract}

Further, 'panel a' on the top-left of Figure 2 of their work shows a schematic drawing of mitochondrial bioenergetics and their experimental strategy. They present themolecular structure of a probe, ${ }_{18} \mathrm{~F}-\mathrm{BnTP}$, whose incorporation into the mitochondria purportedly gives them a bioenergetics' picture, with the scheme driven by the electron transport chain (ETC). I have several concerns with the above aspects. The scheme portrayed (ETC and proton pumps) in the figure is erroneous, as we have pointed out repeatedly $[20,22,25,26]$. TMP is not the driving horse, but the driven cart! And the workers have not measured TMP at all. They have just seen the signal relayed from a molecular probe, which reflects its own chemico-physical state or the nature of its surroundings. The molecule cannot reflect a two-point concept. TMP measurement, as the name suggests, is a two-point phenomenon. In this case, as per Mitchellian proposals, TMP measurements should be made by fine electrodes introduced at two points, one within the matrix and another, within the IMS [22]. No one can do this exercise currently or in any foreseeable future (because there is no technology available for the same). This was a big mistake in bioenergetics field, and we have pointed this out [22]. The molecular probe they have used appears to have a positive Phosphorus center, which can be subject to a reactive oxygen species like superoxide radical. What they noted is no TMP, but the local effects of the reporter molecule by the virtue of its interaction with the various ROS species in milieu. I have also elaborated how FCCP and oligomycin work in mitochondria in the earlier discussion within this paper. The interpretations thereof should be correspondingly corrected.

IV. Nature magazine/journal has continually supported Mitchell's works/ideas and published nonscientific concepts like chemiosmosis/proton motive force for decades. (They did not even acknowledge my repeated requests for rebuttal!) The last review on the subject featured in their sister publication Nature Cell Biology, titled- "The multifaceted contributions of mitochondria to cellular metabolism" by Spinelli and Haigis [40] does not do any justice to the fundamental roles of DROS and the concepts advocated therein need a major overhaul.

V. A recent paper in Science by Murphy et al., from Kuhlbrandt group [41] (titled- Rotary substates of mitochondrial ATP synthase reveal the basis of flexible F1-Fo coupling), delves into the details of how Complex $\mathrm{V}$ makes ATP. The pertinent contents of the abstract are reproduced-

\begin{abstract}
" $F_{1} F_{0}$-adenosine triphosphate (ATP) synthases make the energy of the proton-motive force available for energy-consuming processes in the cell..... Separation of 13 well-defined rotary substates by three-dimensional classification provides a detailed picture of the molecular motions that accompany c-ring rotation and result in ATP synthesis. Crucially, the $F_{1}$ head rotates along with the central stalk and c-ring rotor for the first $\sim 30^{\circ}$ of each $120^{\circ}$ primary rotary step to facilitate flexible coupling of the stoichiometrically mismatched $F_{1}$ and $F_{0}$ subcomplexes...... A conserved metal ion in the proton access channel may synchronize c-ring protonation with rotation."
\end{abstract}

Our works have demonstrated beyond reasonable doubts that Complex V can only serve as a physiological ATPase, not ATPsynthase $[25,26]$. The actual function of ATP synthesis is done by Complexes I through IV. Complex V can bind ADP/ATP and may sponsor some equilibrium driven ATP synthesis also (nobody refutes these facts!), but it has much higher affinity for ATP. Therefore, it is condemned to be an ATP hydrolase, the activity demonstrated for the pure enzyme/protein in vitro too. Other experimental demonstrations in vesicles are equilibrium driven synthesis and such demonstrations have little roles in physiology. (The single-molecule experiments included!) The authors must appraise themselves on the new thermodynamic and kinetic insights we have brought about in the subject.

Regardless, I would like to spar on the structurefunction correlations projected in the paper, with reference to the simplified Complex V structure in Figure 6 of our ABB paper [26]. Differing structures of c-ring obtained could be subtle variations in 3-D structures introduced within the "low-energy" domains and such outcomes can be expected in membrane proteins. The same protein could give multiple conformations with some minor changes. This may or may not have a greater meaning with respect to function. For example- in the mXM system, a membrane protein like CYP2C9 was given two different structures by Harren Jhoti and Eric Johnson groups [42, 43]. Attributing to a metal ion "the ability to rotate the c- 
ring upon protonation" looks far-fetched. Proposing that "the whole head of $\mathrm{F}_{1}$ rotates $25 \%$ for every power stroke of 120 degrees" is not contested, though this could also be speculation. Such thought lines arise from earlier scriptures and strictures because of the assumption that Complex V synthesized ATP via a rotary mode. Complex $\mathrm{V}$ has an asymmetric structure and it is surely a stretched out exercise to envisage that each one of the three $\alpha \beta$ dimers can articulate with the same efficiency with an asymmetric central $y$ stalk in its bottom-core and with the asymmetric $\delta$ connector on its top-side. In this scenario, as per the new proposal, if the $\mathrm{F}_{1}$ head has to move/rotate, it must either rest/draw on the $\delta$ connector on the top and unhinge from the $y$ stalk or it must disentangle from the $\delta$ connector and rotate with the $y$ stalk $+c$ - drum. Given the structural awareness, the latter possibility is much higher because a lateral positioning cannot afford a reproducible torque, whereas a central position can. (Also, there is little mechanistic basis for one to imagine such a scenario as the protons enter via the $c$ - ring side!) On the other hand, if the $\alpha \beta$ dimer-trimer bulb needs to be static, it must have a strong link of the $\alpha \beta$ dimers with the $\delta$ connector at the top and should permit the disconnection between the $y$ stalk and $\alpha \beta$ dimer trimer bulb in the bottom core. So- now the new idea needs a strong connection of the c-drum to the $y$ stalk, a detachable and attachable $\delta$ connector interaction with the $\alpha \beta$ dimer on top, and again a detachable cum attachable connection of the $\alpha \beta$ dimer core with the $y$ stalk at the bottom and the whole or part should be rotated by a few protons moving in adjacent to the c- ring, which should also be held close to the stator $\mathrm{a}+\mathrm{b}$. And then, all these functionalities have to work in absolutely reversible fashion too! This is what I would call the "irreducible complexity" of Michael Behe. Surely, such ideas would have low relevance in reality and evolution. Then, the deciding directive for ATP synthesis would merely lie at the c- ring. If a proton came at the IMS side, it would make ATP and if it came at the matrix side, it would break ATP. Such a setup would end up being a non-directional process. Also, these speculations have no bearing with respect to the thermodynamics, kinetics or the reaction chemistry of ATP synthesis, which is clearly explained better with radical chemistry.

VI. A recent paper by Voila et al. in PNAS titled"Probing electric field across thylakoid membranes in cyanobacteria" grabs my attention next [44]. Select contents of the significance and abstract sections are reproduced- “.....allowing a direct measurement of the transmembrane electric field that develops across their photosynthetic/respiratory membranes. Here, we characterized a probe of the transmembrane electric field.....

In plants, algae, and some photosynthetic bacteria, the ElectroChromic Shift (ECS) of photosynthetic pigments, which senses the electric field across photosynthetic membranes, is widely used to quantify the activity of the photosynthetic chain. In cyanobacteria, ECS signals have never been used for physiological studies, although they can provide a unique tool to study the architecture and function of the respiratory and photosynthetic electron transfer chains, entangled in the thylakoid membranes. .......We demonstrate that these probes are an ideal tool to study photosynthetic physiology in vivo, e.g., the fraction of PSI centers that are prebound by plastocyanin/cytochrome $c_{6}$ in darkness (about $60 \%$ in both cyanobacteria, in our experiments), the conductivity of the thylakoid membrane (largely reflecting the activity of the ATP synthase), or the steady-state rates of the photosynthetic electron transport pathways."

As stated before, the concept of ETC has been disclaimed in aerobic respiration [22] and the same applies to oxygenic photosynthesis too [28] (even though the latter work is unpublished yet). PSI and PSII connectivity cannot be in a $Z$ scheme as it is the violation of fundamental awareness of electronic circuitry. And proton-pump based rationale for ATP-synthesis cannot work in thylakoids either! Further, usage of a dye for measuring "transmembrane electric field" is a clear conceptual flaw, as mentioned earlier. Electric field or potential difference measurements (e.g. as exemplified by a voltmeter) are a two-point concept. A single dye localized on one side of the membrane or within a membrane cannot reflect on something across the membrane. The two regions' 'free electron densities' are to be relatively compared by a reference frame. In this case, the workers used an extended pi-electronic carotenoid molecular system, which is expected to be sensitive and reflective of the local ROS ambience. Therefore, the theoretical concepts assumed and the experimental techniques adopted do not connote the terms used.

VII. Finally, a review authored by Neupane et al. in Biomolecular Concepts in 2019, titled- "ATP synthase: Structure, function and inhibition" [45] is addressed herein.

....Complex $V$ (also known as the $F_{1} F_{0}$ ATP Synthase or ATPase) is responsible for the generation of ATP through phosphorylation of ADP by using electrochemical energy generated by proton gradient across the inner membrane of mitochondria. A multi subunit structure that works like a pump functions along the proton gradient across the membranes which not only results in ATP synthesis and breakdown, but also facilitates electron transport..... 
We have presented several arguments $[20,22,25,26]$ to show that it is not the TMP that enables ATP synthesis and it is not Complex V which functions as physiological ATP synthase. There is no known way how Complex V could facilitate electron transfer, as the ET and ATP-synthesis modules are disconnected in the KMB model. The message of this review needs an overhaul. Our papers, earlier arguments and this write-up's conclusions present the pertinent developments in the field.

\section{Summating against KMB model with 5 points first [22]}

1. The ETC concept cannot explain overall kinetics and is incompatible with the requirement and reactivity of molecular oxygen. Further, this proposal cannot explain the toxicity of cyanide, which is supposed to bind to the same locus as oxygen, and toxicity is seen even in regimes where oxyen can easily out-bind cyanide.

2. The "free proton" availability ( $\sim 6$ at physiological $\mathrm{pH})$ and distribution of membrane redox proteins $\left(\sim 10^{6}\right.$ purported proton translocators) cannot explain a proton-centric bioenergetic or ATP-synthetic paradigm.

3. A bidirectional (co)transport of the very same ions across the very same inner mitochondrial membrane under a 'closed pot' scheme cannot give useful work. Therefore, the $\mathrm{KMB} /$ erstwhile proposal violates thermodynamics and fails to explain reaction stoichiometry with respect to NADH oxidation.

4. ATP synthesis is a simple chemical reaction and it cannot be done by a molecular agent (Complex V) that can hydrolyze ATP better than make it. For this to happen, Complex V must have supramolecular intelligence, which clearly, it does not possess.

5. There is no coherent explanation for the enhancement of reaction rates (enhanced consumption of oxygen and $\mathrm{NADH}$ ) upon the presentation of $\mathrm{ADP} / \mathrm{Pi}$ in the KMB model because ETC is disconnected from ATPsynthesis. The chemical reaction connectivity of NADH oxidation with ATP synthesis is an obligatory and the most salient physiological feature of mOxPhos!

\section{Concluding with 5 points in favor of the murburn paradigm [26]}

1. DROS sponsors ATP-synthesis within both in vitro reductionist and in situ physiological setups. Each one of Complexes I through IV possess ADP-sites and also generate ROS, in the presence of $\mathrm{NADH} /$ succinate and oxygen.

2. The concentration of superoxide/peroxide (reactive oxygen species) produced is directly proportional to $\mathrm{NADH} /$ succinate + oxygen presented and this directly justifies the overwhelming amounts of one-electron centers in the mOxPhos catalytic system.

3. The magnitude of TMP and the amount of ATP synthesized is directly proportional to the ROS detected and ATP cannot be synthesized in mOxPhos without the concomitant production of DROS (superoxide/peroxide). Therefore, catalytic activity of DROS within mitochondria leads to ATP synthesis and it is not TMP that drives ATP synthesis. (While DROS can make a phospho-ester bond and give rise to TMP, TMP cannot make the phospho-ester bond by any known way!)

4. Equations involving the intermediacy and formation of DROS better explain- the overall reaction chemistry (bond-energetics, kinetics, yield, stoichiometry, etc.), account for the reported higher efficiency of mOxPhos, overall phenomenology, the role of Complex $\mathrm{V}$ (coupling agent serving protons in the steady state), structure-function correlations for the reaction components (protein catalysts and reactants), higher distribution density of Complexes III \& IV, etc.

5. Most importantly, DROS mediated synthesis of ATP gives a direct chemical reaction connectivity between electron transfer phenomena and ATP-synthesis/ thermogenesis, explaining greater oxygen uptake and $\mathrm{NADH}$ consumption upon the presentation of ADP+Pi.

I rest my case, and hope that the murburn concept sponsored paradigm shift [20] in cellular metabolism and physiology is evident. Sincerely,

Kelath Murali Manoj

Acknowledgments: KMM would like to thank Vivian David Jacob for proof-reading this letter and credit Adhiatma Therat for figures $2 \& 3$. 


\section{References}

1. Hager LP. A lifetime of playing with enzymes. J Biol Chem. 2010 May;285(20):14852-60.

2. Manoj KM, Hager LP. Chloroperoxidase, a janus enzyme. Biochemistry. 2008 Mar;47(9):2997-3003.

3. Manoj KM, Hager LP. A colorimetric method for detection and quantification of chlorinating activity of hemeperoxidases. Anal Biochem. 2006 Jan;348(1):84-6.

4. Andrew D, Hager LP, Manoj KM. [The intriguing enhancement of chloroperoxidase mediated one-electron oxidations by azide, an active-site ligand.]. Biochem Biophys Res Commun. 2011;414:616.

5. Manoj KM, Hager LP. Utilization of peroxide and its relevance in oxygen insertion reactions catalyzed by chloroperoxidase. Biochim Biophys Acta. 2001 Jun;1547(2):408-17.

6. Murali KM. Chlorinations catalyzed by chloroperoxidase occur via diffusible intermediate(s) and the reaction components play multiple roles in the overall process. Biochim Biophys Acta. 2006 Aug;1764(8):1325-39.

7. Manoj KM. The di-flavoenzyme reductase activates oxygen for the metabolism of diverse drug molecules by liver microsomal cytochrome P450s arXiv preprint 2006, q-bio/0610036v1.

8. Manoj KM, et al. (2016) Drug Metabolism Reviews 48, 41; Metabolism of xenobiotics by cytochrome P450: novel insights into the thermodynamics, kinetics and roles of redox proteins and diffusible reactive species.

9. Venkatachalam A, Parashar A, Manoj KM. Functioning of drug metabolizing microsomal cytochrome P450s: In silico probing of proteins suggests that the distal heme 'active site' pocket plays a relatively 'passive role' in some enzyme-substrate interactions. In Silico Pharmacol. 2016;4(1):2. doi:10.1186/ s40203-016-0016-7

10. Manoj KM, Gade SK, Venkatachalam A, Gideon DA. Electron transfer amongst flavo- and hemo-proteins: diffusible species effect the relay processes, not protein-protein binding. RSC Advances. 2016;6(29):24121-9. https://doi.org/10.1039/ C5RA26122H.

11. Manoj KM, Parashar A, Venkatachalam A, Goyal S, Satyalipsu, Singh PG, et al. Atypical profiles and modulations of hemeenzymes catalyzed outcomes by low amounts of diverse additives suggest diffusible radicals' obligatory involvement in such redox reactions. Biochimie. 2016 Jun;125:91-111. https:// doi.org/10.1016/j.biochi.2016.03.003 PMID:26969799

12. Manoj KM, Parashar A, Gade SK, Venkatachalam A. Functioning of Microsomal Cytochrome P450s: Murburn Concept Explains the Metabolism of Xenobiotics in Hepatocytes. Front Pharmacol. 2016;7:161. doi:10.3389/fphar.2016.00161

13. Manoj KM, Baburaj A, Ephraim B, Pappachan F, Maviliparambathu PP, Vijayan UK, et al. Explaining the atypical reaction profiles of heme enzymes with a novel mechanistic hypothesis and kinetic treatment. PLoS One. 2010 May;5(5):e10601. https:// doi.org/10.1371/journal.pone.0010601 PMID:20498847

14. Manoj KM, Gade SK, Mathew L. Cytochrome P450 reductase: a harbinger of diffusible reduced oxygen species. PLOS ONE 2010;5(10):e13272.

15. Parashar A, Manoj KM. Traces of certain drug molecules can enhance heme-enzyme catalytic outcomes. Biochem
Biophys Res Commun. 2012 Jan;417(3):1041-5. https://doi. org/10.1016/j.bbrc.2011.12.090 PMID:22214932

16. Gade SK, Bhattacharya S, Manoj KM. Redox active molecules cytochrome $\mathrm{C}$ and vitamin $\mathrm{C}$ enhance heme-enzyme peroxidations by serving as non-specific agents for redox relay. Biochem Biophys Res Commun. 2012 Mar;419(2):211-4. https:// doi.org/10.1016/j.bbrc.2012.01.149 PMID:22342667

17. Gideon DA, Kumari R, Lynn AM, Manoj KM. What is the Functional Role of N-terminal Transmembrane Helices in the Metabolism Mediated by Liver Microsomal Cytochrome P450 and its Reductase? Cell Biochem Biophys. 2012;doi:10.1007/ s12013-012-9339-0

18. Parashar A, Gade SK, Potnuru M, Madhavan N, Manoj KM. The curious case of benzbromarone: Insight into super-inhibition of cytochrome P450. PLOS ONE 2014;9(3):e89967. https://doi. org/10.1371/journal.pone.0089967

19. Parashar A, Venkatachalam A, Gideon DA, Manoj KM. Cyanide does more to inhibit heme enzymes, than merely serving as an active-site ligand. Biochem Biophys Res Commun. 2014 Dec;455(3-4):190-3. https://doi.org/10.1016/j. bbrc.2014.10.137 PMID:25449264

20. Manoj KM. Debunking Chemiosmosis and Proposing Murburn Concept as the Operative Principle for Cellular Respiration. Biomedical Reviews. 2017;28(0):31.

21. Parashar A, Gideon DA, Manoj KM. Murburn Concept: A Molecular Explanation for Hormetic and Idiosyncratic Dose Responses. Dose Response. 2018;16(2):1.

22. Manoj KM. Aerobic Respiration: Criticism of the Proton-centric Explanation Involving Rotary Adenosine Triphosphate Synthesis, Chemiosmosis Principle, Proton Pumps and Electron Transport Chain. Biochem Insights. 2018 Dec;11:1178626418818442.

23. Manoj KM, Gideon DA, Jacob VD. [Murburn scheme for mitochondrial thermogenesis]. Biomedical Reviews. 2018;29:73.

24. Manoj KM. [The ubiquitous biochemical logic of murburn concept]. Biomedical Reviews. 2018;29:89.

25. Manoj KM, Parashar A, David Jacob V, Ramasamy S. Aerobic respiration: proof of concept for the oxygen-centric murburn perspective. J Biomol Struct Dyn. 2019 Oct;37(17):4542-56.

26. Manoj KM, Soman V, David Jacob V, Parashar A, Gideon DA, Kumar $M$, et al. Chemiosmotic and murburn explanations for aerobic respiration: predictive capabilities, structure-function correlations and chemico-physical logic. Arch Biochem Biophys. 2019 Nov;676:108128.

27. Jacob VD, Manoj KM. [Are adipocytes and ROS mistaken for villains, or are they protagonists in the drama of life? The murburn perspective. ] [Invited article with cover-page credits; Accepted and in press.]. Adipobiology. 2019;10:1.

28. Manoj KM. Oxygenic photosynthesis: Critiquing the standing explanations and proposing explorative solutions based in murburn concept. OSF Preprints. 2019 Feb. doi:10.31219/osf. io/3mzfp. (Communicated)

29. Manoj KM. Murburn concept explains the acute lethal effect of cyanide. bioRxiv Preprint, 2019 Feb doi: 10.1101/555888.

30. Manoj KM, Bazhin NM. Murburn explanation elucidates (NADH + oxygen + proton)'s metabolic roles in aerobic respiration, connecting it to the experimentally observed trans-membrane potential and water's homeostatic physiological function. OSF Preprints 2019, doi:10.31219/osf.io/hx4p9. 
31. de Montellano PRO. CytochromeP450: Structure, Mechanism, and Biochemistry. Springer International Publishing. Switzerland: 2005.

32. Manikandan P, Nagini S. Cytochrome P450 Structure, Function and Clinical Significance: A Review. Curr Drug Targets. 2018;19(1):38-54. doi:10.2174/1389450118666170125144557

33. Guengerich FP, Yoshimoto FK. Formation and Cleavage of C-C Bonds by Enzymatic Oxidation-Reduction Reactions. Chem Rev. 2018 Jul;118(14):6573-655.

34. Chirumbolo S, Bjorkllund G. PERM Hypothesis: The Fundamental Machinery Able to Elucidate the Role of Xenobiotics and Hormesis in Cell Survival and Homeostasis. Int J Mol Sci. 2017;18(1):165.

35. Nath S. Consolidation of Nath's torsional mechanism of ATP synthesis and two-ion theory of energy coupling in oxidative phosphorylation and photophosphorylation [published online ahead of print, 2019 Nov 14]. Biophys Chem. 2019;106279. doi:10.1016/j.bpc.2019.106279

36. Manoj KM. Refutation of the cation-centric torsional ATP synthesis model and advocating murburn scheme for mitochondrial oxidative phosphorylation. Biophys Chem. 2019; 106278. doi:10.1016/j.bpc.2019.106278

37. Wolf DM, Segawa M, Kondadi AK, Anand R, Bailey ST, Reichert AS, et al. Individual cristae within the same mitochondrion display different membrane potentials and are functionally independent. EMBO J. 2019 Nov;38(22):e101056.

38. Schlame M. Mitochondrial cristae as insulated transformers of metabolic energy. EMBO J. 2019 Nov;38(22):e103472.

39. Momcilovic M, Jones A, Bailey ST, Waldmann CM, Li R, Lee JT, et al. In vivo imaging of mitochondrial membrane potential in non-small-cell lung cancer. Nature. 2019 Nov;575(7782):380-4.

40. Spinelli JB, Haigis MC. The multifaceted contributions of mitochondria to cellular metabolism. Nat Cell Biol. 2018 Jul;20(7):745-54.

41. Murphy BJ, Klusch N, Langer J, Mills DJ, Yildiz Ö, Kühlbrandt W. Rotary substates of mitochondrial ATP synthase reveal the basis of flexible F1-Fo coupling. Science. 2019;364(6446): eaaw9128. doi:10.1126/science.aaw9128

42. Williams PA, Cosme J, Ward A, Angove HC, Matak Vinković D, Jhoti H. Crystal structure of human cytochrome P450 2C9 with bound warfarin. Nature. 2003;424(6947):464-468. doi:10.1038/ nature 01862

43. Wester MR, Yano JK, Schoch GA, et al. The structure of human cytochrome P450 2C9 complexed with flurbiprofen at 2.0-A resolution. J Biol Chem. 2004;279(34):35630-35637. doi:10.1074/jbc.M405427200

44. Viola S, Bailleul B, Yu J, Nixon P, Sellés J, Joliot P, et al. Probing the electric field across thylakoid membranes in cyanobacteria. Proc Natl Acad Sci USA. 2019 Oct;116(43):21900-6.

45. Neupane P, Bhuju S, Thapa N, Bhattarai HK. ATP Synthase: Structure, Function and Inhibition. Biomol Concepts. 2019 Mar;10(1):1-10. 